\title{
Sentidos e significados atribuídos por um grupo de estudantes às tarefas matemáticas
}

\author{
Senses and meanings given by a group of students to mathematical tasks
}

Edmilson Minoru Torisu ${ }^{1}$

\begin{abstract}
Resumo
Sentido e significado são coincidentes? Partindo da discussão em torno dessa pergunta e de alguns dados de uma pesquisa qualitativa, realizada com um grupo de alunos do nono ano do ensino fundamental de uma escola pública de Minas Gerais, os construtos sentido e significado, definidos à luz da Teoria da Atividade são discutidos no contexto da pesquisa. O objetivo é mostrar, partindo das respostas dos estudantes, obtidas por meio de entrevistas semiestruturadas, uma não coincidência entre o significado social e o sentido que eles atribuem às suas participações nas tarefas matemáticas propostas pelo pesquisador, ao longo de um semestre letivo. Essa não coincidência, que costumamos compreender como uma ruptura na aula de Matemática, em nível micro, e na escola de modo geral, em nível macro, pode gerar uma atividade alienada. Os resultados mostram que o significado social da Matemática e da escola, de forma geral, não coincide com o sentido pessoal atribuído pelos estudantes a elas. Ao final, discutem-se algumas possibilidades para a práxis docente como auxiliares na tessitura de uma prática transformadora imbuída do desejo/dever de possibilitar aos estudantes atribuírem novos sentidos à escola.
\end{abstract}

Palavras-chave: Sentido; Significado; Motivos; Alienação.

\begin{abstract}
Are senses and meanings coincidents? Starting from the discussion around this question and some data of a qualitative research, made with a group of ninth's grade student's of a public school of Minas Gerais, the constructs senses and meaning, defined about the aim of Activity Theory are discussed in the research context. The goal is to demonstrate, for the student's answers, obtained by semi structures interviews, a non-coincidence between the social mean and the sense of these participations in mathematics tasks proposed by the researcher, during one semester. This coincidence, that we understand as a break in math class in a micro level, and in the school in general in a macro level, can generate an alienated activity. The results show that the social mean of math and school, in general, doesn't match with the personal sense attributed by the students to them. In the end, some possibilities for teaching praxis as auxiliaries in the fabric of a transforming practice imbued with the desire/duty to enable students to attribute new senses to the school are discussed.
\end{abstract}

Keywords: Sense; Meaning; Reasons; Alienation.

\section{Introdução}

Uma preocupação amplamente propalada na área da Educação em geral e da Educação Matemática, em particular, está relacionada à necessidade de fazer com que as

\footnotetext{
Submetido em: 28/08/2017 - Aceito em: 05/06/2018 - Publicado em: 13/06/2018

${ }^{1}$ Doutor em Educação pela UFMG. Professor Adjunto do Departamento de Educação Matemática (DEEMA) da Universidade Federal de Ouro Preto (UFOP) e professor do Programa de Pós-graduação em Educação Matemática da mesma instituição. Ouro Preto - MG, Brasil. Email: edmilson@iceb.ufop.br
}

Zetetiké, Campinas, SP, v.26, n.2, maio/ago., 2018, p.390-403

ISSN 2176-1744 
disciplinas (e seus conteúdos) tenham significado para os estudantes. Ou será sentido? Sentido e significado são coincidentes?

Nos dicionários, sejam impressos ou webdicionários, é comum encontrarmos a palavra 'sentido' como sinônima da palavra 'significado', e vice-versa. Dependendo do contexto, pode realmente haver uma coincidência entre elas, mas isso não precisa necessariamente ocorrer. Entretanto, que contribuições uma discussão em torno desse assunto pode trazer para a Educação e, sobretudo, para a Educação Matemática?

Esse artigo é uma tentativa de responder a essa questão. Para atingir esse objetivo, buscaram-se subsídios na Psicologia de Alexei Leontiev e Lev Semionovitch Vigotski para analisar alguns dados obtidos em entrevistas realizadas com quatro estudantes do nono ano de uma escola pública da cidade de Belo Horizonte, Minas Gerais. Tais entrevistas foram parte da pesquisa de campo de um estudo de doutorado que buscava saber, dentre outras coisas, os motivos dos estudantes para o envolvimento em tarefas na aula de Matemática. Nesse texto, serão priorizadas as respostas às entrevistas para, a partir delas, realizar uma discussão em torno dos motivos, sentidos, significados e sua relação com o fenômeno social da alienação e suas implicações para o processo educacional.

Os construtos acima citados: sentido, significado e motivos terão papel de destaque na discussão. Sendo assim, a seguir, serão apresentadas as compreensões de cada um deles, baseadas nos referenciais teóricos adotados.

\section{Sentido, Significado, Motivos}

Os conceitos de significado e sentido aparecem na obra de Vigotski nos momentos em que ele discute as relações entre o pensamento e a linguagem. $\mathrm{O}$ autor considera que essa relação é a chave para a compreensão da consciência humana, cuja atividade não é apenas cognitiva e intelectual, pois apresenta também uma dimensão afetiva. Ao fazer isso, Vigotski coloca em relevo a dialética da constituição da consciência, a integração entre cognição e afeto e o caráter social e histórico da formação do indivíduo (Aguiar, 2007).

Para Vigotski, o significado é uma construção social, quase estável. O sentido, por sua vez, é formado a partir do confronto entre os significados sociais vigentes e a experiência pessoal. Visto dessa forma, o sentido é mais complexo que o significado sendo que este pode ser considerado apenas como uma zona do sentido, mais estável e precisa (Aguiar, 2007), aquilo que é compartilhado em diferentes contextos sociais. Nas palavras de Vigotski (2000, p.465),

[...] o sentido é sempre uma formação dinâmica, fluida, complexa, que tem várias zonas de estabilidade variada. O significado é apenas uma dessas zonas do sentido que a palavra adquire no contexto de algum discurso e, ademais, uma zona mais estável, uniforme e exata. Como se sabe, em contextos diferentes, a palavra muda facilmente de sentido. O significado, ao contrário, é um ponto imóvel e imutável que permanece estável em todas as mudanças de sentido da palavra em diferentes contextos. 
O sujeito produz sentidos do vivido, daquilo que ele internaliza, compartilhando esses sentidos subjetivos em suas relações sociais (Aguiar, 2007). O processo de internalização transforma o social em subjetivo e isso é uma nova produção. A nova produção é colocada no social, modificando-o. Essa é a essência da relação dialética entre o externo e o interno.

Contudo, os estudos de Vigotski relacionados ao significado parecem ter se concentrado no significado da palavra, não considerando o contexto mais amplo da atividade. "Logo, a noção de significado de Vigotski parece aderir à visão representacional de linguagem. A essência do significado da palavra é o ato de pensamento [...]. O pensamento parece representar a realidade e ser representado pela linguagem" (Lampreia, 1999, p. 8).

Alexei Leontiev, discípulo de Vigotski, aprofundou a análise do conceito de sentido relacionando-o com a atividade mais ampla, considerada como elemento mediador entre o sujeito e a realidade objetiva. Em seu livro intitulado $O$ desenvolvimento do Psiquismo, o psicólogo russo nos apresenta suas ideias sobre sentido e significado. Leontiev (1978a) utiliza os termos significação ou significado social e sentido pessoal para aquilo que estamos chamando de significado e sentido, respectivamente.

Para o autor, significação é o reflexo da realidade e independe da vontade do indivíduo, ou seja, é a forma sob a qual o homem se apropria da experiência humana historicamente construída, independentemente da relação individual ou pessoal que estabelece com ela. Podemos ainda dizer que é a entrada na consciência humana do reflexo generalizado e fixado de um saber, de um saber-fazer, de modos de ação, normas de comportamento. Ao nascer, o homem encontra um sistema de significações provisoriamente pronto, construído historicamente e apropria-se dele tal como se apropria de um instrumento, precursor material da significação (Leontiev, 1978a).

O sentido, como fato psicológico, é uma interpretação pessoal da significação (Leontiev, 1978a) e, por isso, varia de pessoa para pessoa. É como um 'significado para mim `. A significação é algo mais ou menos pronto e mais ou menos parecido para um mesmo grupo em determinado momento histórico, ao passo que o sentido é pessoal e depende do percurso de vida de cada um. Nas palavras de Asmolov (1984, apud Rey, 2007, p. 166):

O sentido pessoal representa o reflexo individualizado do mundo, que inclui a relação
da personalidade com aqueles objetos pelos quais se desenvolve sua atividade e sua
comunicação. As mais diversas manifestações da cultura, e mais amplamente, das
relações sociais, assimiladas pelo sujeito no processo de interiorização das normas
sociais, conceitos, papéis, valores e ideais percebidos por ele nos atos e ações de
outras pessoas, podem, adquirir para ele sentido pessoal, se transformando em
"significados para mim".

$\mathrm{Na}$ literatura, podemos encontrar vários exemplos que diferenciam significado de sentido. No entanto, para a coerência desse texto, apresenta-se um exemplo relacionado à escola. A despeito de todas as mudanças pelas quais essa instituição tem passado ao longo dos anos, costuma-se dizer que o seu significado social é o de um local para onde as pessoas vão para aprender, desenvolver-se intelectualmente e como ser humano. 
Entretanto, quem são os principais atores da escola? Quem busca conhecimentos nesse local? Sabemos que são os estudantes e que cada um possui uma forma particular de enxergar o ambiente escolar como espaço de aprendizagem. Isso é o seu sentido pessoal. Uma criança pequena pode enxergar a escola como uma possibilidade de mudar o lugar que ela ocupa nas suas relações sociais porque vai adquirir novos conhecimentos valorizados pelos adultos. Para um adolescente, a escola pode representar várias coisas: local para estreitamento de laços de amizade; local hostil, dada a rejeição que sofre por parte de colegas e professores; local onde se come para saciar a fome do que não se tem em casa; local para aprender conteúdos importantes para a vida futura. Nesses casos, o aprender assume contornos muito distintos. Em casos extremos, podemos pensar ainda nas crianças para as quais a escola é só um sonho. Percebemos que são muitos os sentidos pessoais atribuídos à escola.

Motivo será compreendido no arcabouço teórico da Teoria da Atividade (TA), desenvolvida por Leontiev e cuja base é a Teoria Histórico-cultural desenvolvida por Vigotski. Não é intenção deste artigo discorrer longamente sobre tal teoria, mas julgo necessário apresentá-la minimamente para localizar o construto motivo em sua estrutura.

A TA tem sua base filosófica no materialismo histórico-dialético proposto por Marx, segundo o qual o desenvolvimento social do homem e da sua própria individualidade se dá na sua participação em atividades coletivas. Ao participar de tais atividades, o homem se apropria dos conhecimentos historicamente construídos desenvolvendo-se e provocando mudanças no seu entorno. Dessa forma, a relação entre homem e meio é uma via de mão dupla, uma relação dialética (Kozulin, 2002).

De acordo com Leontiev (1978b) a atividade humana é sempre coletiva, surge de uma necessidade e é guiada por um motivo rumo a um objeto, que satisfará tal necessidade. $\mathrm{O}$ motivo é aquilo que move o indivíduo rumo às ações e ao engajamento na atividade. Mas alguém pode questionar: por que discutir sobre motivos? Porque há uma relação íntima entre motivo e sentido.

Para ilustrar essa relação vou utilizar um exemplo de Leontiev (1978a), no qual um aluno lê um livro. De acordo com o autor, motivos diferentes para a leitura estão associados a sentidos diferentes.

Se o motivo consiste em preparar o estudante para sua futura profissão, a leitura terá um sentido. Se, em contrapartida, se trata, para o leitor de passar nos exames, que não passa de uma simples formalidade, o sentido de sua leitura será outro. Ele lerá a obra com outros olhos; assimilá-la-á com outros olhos (Leontiev, 1978a, p. 79).

Para Asbahr (2005), a aprendizagem e a conscientização de um saber dependem do sentido que ele tem para o estudante. E, de acordo com o exemplo acima, para sabermos o sentido precisamos saber o motivo, de modo que devemos enxergá-los como construtos intimamente relacionados. 
Vimos, também, que sentido e significado podem ser coincidentes. No entanto, se não houver essa coincidência, o que ocorrerá? É sobre esse assunto que trataremos, a seguir.

\section{Alienação}

Leontiev (1978a) nos informa que a divisão do trabalho e a propriedade privada produziram, na consciência humana, uma dissociação entre o significado e o sentido da ação, ao que ele denominou alienação. $\mathrm{O}$ autor ilustra o fenômeno da alienação por meio de um exemplo do trabalho em uma tecelagem.

A tecelagem tem (...) para o operário a significação objetiva da tecelagem, a fiação de fiação. Todavia não é por aí que se caracteriza sua consciência, mas pela relação que existe entre estas significações e o sentido pessoal que têm para elas as suas ações de trabalho. Sabemos que o sentido depende do motivo. Por consequência, o sentido da tecelagem ou da fiação para o operário é determinado por aquilo que o incita a tecer ou a fiar. Mas são tais as condições de existência que ele não fia ou não tece para corresponder às necessidades da sociedade em fio ou em tecido, mas unicamente pelo salário; é o salário que confere ao fio e ao tecido o seu sentido para o operário que os produziu (Leontiev, 1978a, p. 131).

O operário tem conhecimento da significação social de seu trabalho e do que ele representa na sociedade. Contudo, não trabalha porque supõe que sua função seja importante para seu país, mas pelo salário que lhe trará condições de sobrevivência. Esse é, para ele, o sentido pessoal. Essa ruptura entre significado social e sentido pessoal o aliena e o priva de outros conhecimentos, do processo como um todo. "Esse dualismo desnatura os sentimentos mais elementares no homem" (Leontiev, 1978a, p. 133). No caso da escola, o significado social é o de um local de socialização de conhecimentos que possibilitarão a um indivíduo constituir-se como homem. No entanto, será este o sentido atribuído pelos estudantes à escola?

A seguir, serão apresentadas informações gerais sobre uma pesquisa de doutorado, da qual selecionamos, para esse texto, respostas dadas a duas entrevistas. A partir dessas respostas, uma discussão em torno dos construtos sentido pessoal, significado social, motivos e sua relação com o fenômeno da alienação será realizada.

\section{Aspectos metodológicos}

A pesquisa, de cunho qualitativo, foi realizada com um grupo de quatro estudantes do nono ano de uma escola pública da cidade de Belo Horizonte, Minas Gerais. Seus nomes fictícios eram Paulo, Lauro, Leandro e Gabriel.

A escola fica localizada dentro do campus de uma universidade pública e o ingresso dos estudantes ocorre logo no primeiro ano do Ensino Fundamental, por meio de sorteio. Estudantes de todos os lugares podem concorrer a uma vaga. Outra característica que torna grande a procura por essa escola está no fato de ela garantir vaga, sem processo seletivo, em um colégio técnico renomado, tão logo os estudantes concluam o ensino fundamental. 
Após autorização da direção e da professora, aos estudantes foram propostas tarefas matemáticas investigativas na aula de Matemática, ao longo de um semestre letivo. De acordo com Ponte, Brocardo e Oliveira (2009), uma tarefa investigativa difere de um simples exercício quando não apresenta um caminho a ser seguido e permite que o aluno explore, podendo encontrar caminhos diferentes, todos corretos. A resposta também não precisa ser única. Outra perspectiva de investigação denominada cenários para investigação é apresentada por Skovsmose (2000). Os cenários para investigação se opõem ao paradigma do exercício, abordagem de ensino que prioriza conteúdos e técnicas matemáticas para a resolução de listas de exercícios. Diferentemente disso, nos cenários para investigação o aluno é convidado a participar de seu processo de aprendizagem com um olhar crítico.

Dentre as tarefas propostas aos alunos, havia várias possibilidades de exploração: planos de telefonia celular, contas de energia elétrica, ampliação de figuras, sequências lógicas, dentre outras. Na tarefa relacionada a planos de telefonia celular, por exemplo, os estudantes deveriam criar o perfil de um cliente hipotético para, dentre várias opções de planos $^{2}$, oferecidos por uma empresa de telefonia, também hipotética, escolher aquele que melhor atenderia o usuário, em termos de serviços e com menor custo, de acordo com o perfil criado. A criação do perfil pelo grupo foi influenciada pelos próprios usos que os integrantes faziam de seus telefones celulares. As características de seus ambientes sociais, em alguma medida, se faziam presentes em suas escolhas.

Um dos objetivos da pesquisa era desvelar os motivos dos estudantes para a participação nas tarefas. Motivo, como um construto da TA, foi compreendido como aquilo que move o sujeito a se engajar em algo. No caso da pesquisa, se engajar nas tarefas. $\mathrm{O}$ motivo é de caráter social e, embora possa ser individual, emerge no desenrolar de nossas vidas em um coletivo. Isto corrobora as ideias de Chaiklin (2012) quando ele nos alerta para o fato de que "motivo é um conceito individual e coletivo. Indivíduos podem ter motivos, mas a individualidade dos motivos é sempre tecida dentro da prática social" (Chaiklin, 2012, p. 219).

Nesse sentido, após as tarefas, duas entrevistas forma realizadas com os estudantes. A primeira delas, com todo o grupo, ocorreu no final do ano letivo de 2012. A segunda, que foi individual, ocorreu no primeiro semestre de 2013.

A entrevista é uma técnica de coleta de dados recorrentemente utilizada em pesquisas qualitativas. De acordo com Alves- Mazzotti e Gewandsznajder (1998), ela permite explorar temas complexos que dificilmente poderiam ser abordados somente com o uso de questionários. Como o interesse era explorar motivos dos alunos para a participação em tarefas matemáticas e isso significava, em alguma medida, obter informações mais pormenorizadas de suas vivências em grupos sociais, a utilização das entrevistas pareceu bastante adequada. Ao responderem as perguntas, os estudantes falavam por/de si, mas essas falas traziam embutidos matizes de falas de outras pessoas com as quais eles conviviam em

${ }^{2}$ As características desses planos eram apresentadas aos estudantes.

Zetetiké, Campinas, SP, v.26, n.2, maio/ago., 2018, p.390-403

ISSN 2176-1744 
seus grupos. Isso é coerente com as ideias de Freitas (2002, p. 29) sobre entrevistas em pesquisas qualitativas de cunho sócio-histórico quando a autora afirma que "na entrevista é o sujeito que se expressa, mas sua voz carrega o tom de outras vozes, refletindo a realidade de seu grupo, gênero, etnia, classe".

Foi por meio dessas entrevistas que foram acessados os motivos dos estudantes. $\mathrm{Na}$ próxima seção, serão apresentadas algumas respostas dos estudantes às entrevistas.

\section{Em busca de motivos}

A primeira entrevista foi guiada por uma pergunta diretriz: Quando vocês se envolvem neste tipo de tarefa em sala de aula, há um por que principal? Se sim, qual?

A seguir, algumas respostas dos estudantes:

Paulo: Eu acho que a gente faz pensando no futuro, né? (pausa) se a gente precisar fazer..., igual lá, tem os cálculos lá que a gente ... aí, vai que no futuro a gente precisa, né? ${ }^{3}$

Lauro: [...] eu acho que tem um porque sim. Porque, de certa forma ele passa algumas atividades relacionadas à Matemática, mas também cotidianas [...]algumas coisas que você pode relacionar com o cotidiano que te ajudam. A própria questão do celular e tudo.

Pesquisador: Então você acha que a matemática, não toda né, em algum momento ela pode te ajudar depois, no seu cotidiano?

Lauro: Exatamente, num futuro trabalhista.

Gabriel: Mais por causa do dia a dia mesmo... a gente pode precisar do negócio lá... aí a gente sabe fazer qual vale a pena.

Leandro: Eu também era daqueles alunos que pensava assim ... pra que eu tô usando isso ai? Ai, depois veio aquela do celular e eu entendi mais ou menos porque que a gente tava fazendo aquilo... porque tipo assim, às vezes você tinha um plano do jeito que você queria mas você podia achar um mais barato, dependendo da quantidade... aí vi que você pode usar no dia a dia, igual todo mundo falou assim.

Nos grupos sociais dos quais fazemos parte somos instados a ouvir opiniões acerca da Matemática. Às vezes é considerada uma disciplina difícil. Em outros momentos seus conteúdos são exaltados e considerados imprescindíveis para o dia a dia e para o futuro. Com o passar do tempo nos apropriamos desses discursos que, muitas vezes, passam a ser verdades que reproduzimos. A partir dessas ideias é razoável pensar que um motivo dos estudantes para participarem das tarefas era aprender uma Matemática útil para o cotidiano. Contudo, seria esse o único motivo relativo à Matemática?

De acordo com a concepção de motivo como algo que emerge das relações sociais, a resposta é não. Sendo assim, uma segunda entrevista foi realizada com os estudantes, agora individualmente. Não havia uma pergunta diretriz e suas vivências em grupos foram privilegiadas. A entrevista teve um tom de bate-papo, no qual procurou-se saber um pouco

\footnotetext{
${ }^{3}$ Optei por não fazer correções nas respostas dos estudantes para mantê-las fiéis ao que me foi dito. 
mais sobre família, escola, relação com a Matemática e futuro. As respostas poderiam apontar pistas de novos motivos.

A seguir, os quatro estudantes serão apresentados com mais detalhes. Serão apresentadas, também, algumas de suas falas durante a segunda entrevista, que foram categorizadas para tornar o texto mais didático.

Paulo: Tinha 15 anos, à época da pesquisa. Embora elogiado pela professora e reconhecido pelos colegas como um aluno exemplar e de excelentes resultados nas provas, isto não parecia envaidecê-lo. Era dedicado, participativo mas não falava muito. Morava em um condomínio fechado na região metropolitana de Belo Horizonte com os pais e mais um irmão. A situação financeira da família era confortável.

Leandro: Diferente de Paulo, Leandro era muito falante e tinha 14 anos. Morava em um bairro da região metropolitana de Belo Horizonte com a mãe, o padrasto e mais quatro irmãos. Ao falar de sua família, centrou-se na mãe e em um dos irmãos. A mãe de Leandro era vendedora no centro da cidade e cumpria uma rotina diária de trabalho bastante cansativa.

Gabriel: Era o mais calado do grupo. Muito tímido, exibia um sorriso 'envergonhado' sempre que era questionado sobre alguma coisa. Tinha 16 anos à época da pesquisa. Ele havia sido reprovado duas vezes na escola e, por essa razão, estava fora da faixa etária comumente encontrada em turmas de nono ano. Estas reprovações provocaram sentimentos negativos em relação ao espaço escolar. Morava em um bairro da periferia de Belo Horizonte com os pais, uma irmã e mais três pessoas.

Lauro: Tinha 14 anos quando estive em sua sala. Não falava muito, mas quando o fazia, expunha com clareza suas ideias. Não utilizava muitas gírias como é comum entre os adolescentes. Embora os pais fossem separados, mantinham boa relação. Morava com a mãe e passava os fins de semana com o pai. A situação financeira da família era confortável. Fazia aulas de inglês e tênis.

As categorias criadas para agrupar as falas dos estudantes foram as seguintes: família, escolha da escola, Matemática e futuro. Essas categorias foram construídas de forma indutiva já que, nesta construção, foram utilizados dados do corpus (Moraes, 2003). Durante a observação e leitura dos dados, por um processo de comparação, elementos semelhantes das respostas foram reunidos em conjuntos que deram origem às categorias.

\section{Família}

Paulo: A minha família é fundamental para minha vida, dentro e fora da escola. Eles me proporcionam ótimas condições de estudo, como por exemplo: compram o livro que minha escola sugere, atendem a todas as minhas reclamações em termos de condições de estudo. A minha família me apoia muito com meus estudos, principalmente a minha mãe. Várias vezes ela deixa de sair para se divertir para ficar em casa comigo porque eu tenho que estudar. Além disso, o fato de eles me darem tudo o que eu peço me motiva estudar cada dia mais para mostrar para eles que estou fazendo valer a pena. $O$ apoio dos meus pais quando as coisas não dão 
certo também é muito importante, pois me motiva a não desistir e me mostra a minha capacidade. ${ }^{4}$

Leandro: Ela mesma fala que a única coisa que ela está deixando para mim é o estudo. Minha mãe fala isso todo dia praticamente. Lá em casa a minha mãe apostou tudo em mim, porque o meu irmão 'do meio' não está nem aí para nada. Minha mãe falou: olha, eu já abri mão dele, porque eu sei que ele tem problema. Agora tá em você $\hat{e}^{5}$.

Gabriel: Todo mundo almoça junto. Só meu pai que chega tarde. Aí ele almoça separado. Fora isso almoça e janta todo mundo junto. Aí, domingo almoça todo mundo junto. Incentivam (os estudos) e quando eu tô com dificuldade eu falo com eles... que nem Português. Agora eu tô fazendo aula particular e tal, desde o ano passado. Que eu tenho dificuldade em português. Aí eu comecei.

Lauro: Que moram comigo, eu e minha mãe, porque a minha irmã já é mais velha... aí ela tem filhos... aí ela mudou e meu pai é separado.

\section{Escolha da escola}

Paulo: A escolha de ir para o CP não foi minha. Na verdade eu estudei durante a $1^{a}$ série em uma escola de meu bairro [...]. Porém, por grande pressão de minha mãe, meu pai me inscreveu no sorteio do CP e eu fui sorteado, então mudei de escola porque minha família considerava o CP melhor por vários aspectos, como: fica dentro da universidade, me direciona para o Colégio Técnico e etc.

Leandro: A minha mãe ficou sabendo por uma amiga dela que a escola era uma escola boa, dentro da [...]. Aí quando você fala que estuda dentro da [...] parece que... Aí minha mãe foi lá e fez a inscrição.

Gabriel: Minha mãe ficou sabendo, não me lembro por quem... eu sei que ela ficou sabendo e me inscreveu lá no sorteio. Aí eu fui sorteado. Ela colocou também pensando no Colégio Técnico e esses negócios...

Lauro: Olha, na verdade quem escolheu o CP foi meu pai, pela passagem direta para o Colégio Técnico mesmo ${ }^{6}$. Ele que foi lá e fez o sorteio. Aí, quando eu passei foi a felicidade maior dele.

\section{Matemática}

Paulo: Minha relação com a matemática, até o $8^{\circ}$ ano, foi sempre normal. Mas a partir do $8^{\circ}$ ano eu me apaixonei por Matemática, só não gostava mais do que Educação Física. Agora no CP continuo gostando muito de Matemática e isso é fundamental, pois esse meu gosto me facilita a aprender as coisas em sala, e como eu não tenho muito tempo para estudar essa matéria em casa devido ao fato de eu dar prioridade ao curso técnico ${ }^{7}$. Então esse meu gosto por matemática sempre me ajudou muito.

Leandro: Eu não me dou muito bem com a Matemática não. Às vezes eu erro muita coisa boba e tiro nota ruim. [...] a matéria foi ficando mais difícil e eu deixei de gostar.

Gabriel: Tipo, eu não sou muito bom em Matemática, mas, tipo, se tiver que escolher entre fazer exatas, humanas e esses negócios, eu acho que eu vou me dar melhor em

\footnotetext{
${ }^{4}$ Os textos foram transcritos como foram apresentados.

${ }^{5}$ Acredito que seja algo como: agora a responsabilidade é sua.

${ }^{6}$ Omissão do nome da escola para onde o aluno iria após finalizar o nono ano.

${ }^{7}$ Esta parte está confusa. O fato de gostar muito de Matemática parece lhe permitir se dedicar mais às matérias técnicas, que são sua prioridade.
}

Zetetiké, Campinas, SP, v.26, n.2, maio/ago., 2018, p.390-403

ISSN 2176-1744 
exatas.

E justificou (mesmo não se considerando bom aluno em Matemática) sua escolha por ciências exatas, com as seguintes palavras:

Gabriel: É porque tipo, ninguém quer ser pobre. Aí, pra mim, tipo, ser rico e tal eu vou ter que estudar, mesmo que eu não goste daquilo e tal, vou ter que me dedicar de qualquer jeito.

Lauro: Na escola eu sempre fui bem em Matemática. Sempre gostei também. Só que nono ano eu tive um desempenho muito baixo na primeira etapa, por causa de questões de família. Meu avô estava internado. Eu tava abalado e também tava tendo dificuldade na matéria. Só que, na segunda etapa, quando entrou uma matéria nova e eu comecei prestar atenção, aí já voltei a me dar bem.

\section{Futuro}

Paulo: Ainda não sei se vou fazer curso superior, depende muito do meu futuro, se eu conseguir um bom emprego como técnico, talvez eu nem pense em faculdade. Eu escolheria, hoje, cursar Ciência da Computação porque é uma matéria em que eu me identifico muito.

Leandro: Depende se, tipo assim, se eu ver que o salário, a remuneração do curso que eu tenho está muito alta e se eu fizer um curso superior não vai fazer muita diferença, vou continuar fazendo o técnico. [...] vou ver como é que é primeiro ${ }^{8}$. Aí, se eu vir que não é necessário ir para a faculdade eu vou continuar exercendo o técnico. [...] Meus interesses são os seguintes: eu queria ter uma empresa. Eu queria comandar a empresa, mas para tudo você precisa saber alguma coisa. Administração é exatas, eu não vou conseguir fugir da Matemática. [...] eu gosto da área de exatas, mesmo tendo esses problemas todos, eu ainda vou para o lado de exatas. [...] a minha preocupação é esta: dar alguma coisa para a minha mãe.

Gabriel: Mas tipo, eu tô pensando o seguinte: se eu gostar do técnico, eu vou trabalhar com ele. Aí, se eu ver que não tá muito bom, aí tipo, eu pretendo fazer Educação Física, ou então alguma coisa na área de exatas. Eu quero formar aqui, primeiro. Fazer estágio, trabalhar um tempo no técnico, ver se eu gosto. Se eu não gostar vou entrar numa boa faculdade, ter minha casa, esses negócios.

Lauro: Eu quero fazer Engenharia de Software. Já vou fazer direto.

Dessas falas, que motivos emergiram?

A família, para todos os estudantes, era nuclear e de grande importância para as suas vidas. Independentemente da situação financeira e das dificuldades que poderiam enfrentar, a ela os estudantes deviam muito respeito. Ligado à família, então, podemos pensar no motivo cumprir o papel de estudante para satisfazer às expectativas dos pais.

$\mathrm{Na}$ categoria escolha da escola podemos notar, claramente, que o interesse das famílias na escola dos filhos estava relacionado à vaga no colégio técnico. Os estudantes, ao se apropriarem disso, tentavam se empenhar para obterem êxito ao final de seus anos escolares. Podemos falar do motivo estudar para ingressar na escola técnica.

Na categoria Matemática podemos falar do motivo gostar de Matemática. Entretanto, somente para Paulo e Lauro. Ao que pareceu, Leandro e Gabriel não eram movidos por esse 
motivo para participarem das tarefas, dada a relação nada amigável com essa disciplina.

Em relação ao futuro, todos pareceram concordar que a Matemática era importante para o sucesso profissional. Estamos tratando aqui do motivo saber Matemática para um futuro de sucesso.

Além desses motivos que emergiram na segunda entrevista, ainda há aquele que foi explicitado pelos estudantes na primeira entrevista: aprender uma Matemática útil para o cotidiano.

Conectados a esses motivos parece haver três sentidos pessoais principais, válidos para todos eles e relacionados ao envolvimento nas tarefas propostas:

1) Participar das tarefas tem o sentido de dar satisfação aos familiares pelos esforços que destinam à educação;

2) Participar das tarefas tem o sentido de querer aprender uma Matemática que os beneficiará no dia a dia e no futuro.

3) Para Paulo e Lauro, participar das tarefas também tem o sentido de realizar algo prazeroso para eles, que são as tarefas matemáticas.

O primeiro desses sentidos está mais relacionado à escola, de forma geral. No segundo e terceiro, a Matemática fica em relevo. Contudo, serão esses os significados sociais da escola e da Matemática?

Historicamente, o significado social da escola é de um local onde se vai para adquirir conhecimentos e crescer intelectualmente. Nas palavras de Mendonça (2011, p. 349)

A escola é o espaço singular para as mediações, que visam à socialização dos conhecimentos, a partir de atividades pedagógicas organizadas para esse fim, em cuja condução o professor tem um papel fundamental de fazer a articulação entre esses conhecimentos (significados sociais) e os conhecimentos dos estudantes (sujeitos que atribuirão sentido pessoal a essas práticas sociais consolidadas).

O ideal seria, então, que o trabalho pedagógico fosse capaz de gerar, nos estudantes, motivos e sentidos para participarem da vida escolar que se aproximassem desse significado social. Caso contrário, a atividade escolar do estudante seria alienada, privando-o da experiência real de aprendizagem.

Voltando à pergunta anterior: serão esses os significados sociais da escola e da Matemática?, a resposta parece ser não. Os sentidos pessoais dos estudantes parecem distantes do citado significado social da escola. Os estudantes até reconhecem o seu significado social, mas não é esse o sentido que eles lhe atribuem.

Nas relações que estabelecem ao longo da vida, as pessoas se apropriam de discursos sociais que passam a assumir como seus. A ruptura entre sentido e significado da escola, a alienação, ocorre não só para o estudante, mas para a sociedade. Dessa forma, o sentido pessoal da escola e da participação em suas atividades é, para o estudante, uma consequência do sentido pessoal que ela tem para a sociedade. Isso corrobora as ideias de Duarte (2004), 
embora o exemplo não seja relacionado à escola, quando ele escreve:

$\mathrm{Na}$ verdade, o sentido pessoal que o trabalho tem para o operário é uma consequência do sentido que esse trabalho tem para a sociedade capitalista. No caso da sociedade, essa dissociação entre o conteúdo do que é produzido e o sentido que tem a produção se reflete na separação e muitas vezes no conflito entre a chamada esfera econômica e as demais esferas da vida social (Duarte, 2004, p. 58).

No caso específico da Matemática, isso talvez se deva ao que Borba e Skovsmose (2001) denominam Ideologia da Certeza, um conjunto de crenças que dão à Matemática o poder de conter o argumento definitivo e inquestionável. De acordo com os mesmos autores, frases como 'foi provado matematicamente', 'os números expressam a verdade', 'os números falam por si mesmos', 'as equações mostram que'... são frequentemente usadas na mídia e nas escolas" e colocam em relevo a importância dada à Matemática e servem como argumentos inquestionáveis sobre o seu poder.

Naturalmente, quando disseminada, essa ideologia reverbera, podendo provocar a ruptura tratada acima. Pode-se notar a apropriação do discurso social em torno do poder da Matemática em várias falas dos estudantes:

Lauro: "Mesmo se eu não gostasse de Matemática eu vejo Matemática como um conteúdo de extrema importância. Matemática e Português, pra mim, são as disciplinas de maior importância pelo social. Eu acho importante a Matemática tanto no social quanto no seu futuro de trabalho entre outros".

Gabriel: "É porque tipo, ninguém quer ser pobre. Aí, pra mim, tipo, ser rico e tal eu vou ter que estudar, mesmo que eu não goste daquilo e tal, vou ter que me dedicar de qualquer jeito" 9 .

Leandro: "Administração de empresas. Meus interesses são os seguintes: eu queria ter uma empresa. Eu queria comandar a empresa, mas para tudo você precisa saber alguma coisa. Administração é exatas, eu não vou conseguir fugir da Matemática. A minha preocupação é esta: dar alguma coisa para a minha mãe.

Lauro considera o conteúdo matemático de extrema importância para sua vida social e para seu futuro. Gabriel chega a atribuir à Matemática o poder de torná-lo rico, enquanto Leandro acredita que para obter sucesso em sua sonhada empresa, a Matemática terá papel decisivo. De forma geral, para os quatro estudantes, o interesse em aprender Matemática não parece ser algo per se, mas pelo lucro financeiro que ela pode lhes proporcionar. Uma passagem de Leontiev (1978a, p. 132), parece traduzir bem essa ideia: "A alienação das relações pessoais dos homens e a sua transformação em puras relações entre coisas manifestam-se de maneira flagrante no poder que o dinheiro, modo de troca universal, tomou sobre a vida do homem". Para esses estudantes, a Matemática parece ser sinônimo de dinheiro.

Não é o caso de negar a importância da Matemática na sociedade moderna. Sabemos que ela é importante e, em alguns casos, motor de desenvolvimento. O que devemos ter é uma postura crítica diante dessa situação para mudar tais crenças, que poderia se iniciar com

\footnotetext{
${ }^{9}$ Esta resposta foi dada por Gabriel na segunda entrevista. Ele afirmara não gostar de Matemática. Mesmo assim, acreditava que precisava estudar Matemática porque ela poderia ajudá-lo a ficar rico.
}

Zetetiké, Campinas, SP, v.26, n.2, maio/ago., 2018, p.390-403

ISSN 2176-1744 
o professor. No entanto, talvez as próprias condições de trabalho do professor o alienem, fazendo com que o sentido de seu trabalho seja o salário no fim do mês e não oferecer as melhores condições de aprendizagem a seus alunos.

\section{Algumas considerações finais}

No cenário atual, a escola não tem sido vista como o espaço que deveria ser: de socialização de conhecimentos e promotora da emancipação do homem. Contudo, isso não nos habilita a desconsiderá-la pois, como instituição historicamente construída, tem papel importante no desenvolvimento da humanidade. É necessária uma aproximação mais coerente entre seu significado social e os sentidos dados a ela. Isso porque, o sentido da escola para a própria sociedade, tem sido enviesado, talvez pela lógica capitalista. Isso influencia diretamente o sentido que os estudantes atribuem à escola, já que as relações sociais estabelecidas pelos estudantes em grupos distintos (família, escola, igreja, amigos, etc) não são estanques e se influenciam mutuamente.

No caso da Matemática, a dissociação entre sentido e significado parece ser ainda mais evidente. As crenças em torno dessa disciplina que geram a ideologia da certeza garantem a ela um poder que não é real, mas do qual temos nos apropriado. Como consequência, a Matemática tem servido para separar os estudantes em dois grupos: os que aprendem e os que não aprendem Matemática. E quando foi esse o objetivo da aprendizagem matemática?

A sociedade precisa resgatar o sentido histórico da escola. Entretanto, como sabemos, essa tarefa é difícil e deve ser realizada a várias mãos. Será necessário um esforço conjunto de todos os atores envolvidos, sobretudo famílias, professores e alunos. Particularmente, os professores poderiam mudar a sua atividade prática para uma práxis diária pois, diferentemente da prática que tem parecido por demais pragmática, a práxis, no sentido marxista, é uma atividade consciente que se pretende intencional e transformadora.

Retomando a pergunta feita no início do texto: que contribuições uma discussão em torno desse assunto pode trazer para a Educação e, sobretudo, para a Educação Matemática?, podemos ter claro que a própria discussão, em si, já é uma contribuição. Sabemos que as mudanças necessárias na escola e citadas em parágrafos anteriores não se darão sem empenho, esforço e reflexões em torno do assunto. Esse texto foi uma tentativa de levar-nos à reflexão, como um pequeno passo rumo às desejadas mudanças.

\section{Referências}

Aguiar, W. M. J. (1998). Consciência e Atividade: categorias fundamentais da psicologia sócio-histórica. In A. M. B. Bock, M. G. M. Gonçalves \& O. Furtado, Psicologia sóciohistórica: uma perspectiva crítica em psicologia (pp. 95-112). São Paulo: Cortez. 
Alves-Mazzotti, A. J., \& Gewandsznajder, F. (1998). O método nas ciências sociais. In A. J. Mazzotti, F. Gewandsznajder, O método nas ciências naturais e sociais: pesquisa quantitativa e qualitativa (pp. 147 - 178). São Paulo: Pioneira.

Asbahr, F. S. (2005). A pesquisa sobre a atividade pedagógica: contribuições da Teoria da Atividade. Revista Brasileira de Educação, (29), 108-118.

Borba, M. C., \& Skovsmose, O. (2001). A ideologia da certeza em Educação Matemática. In O. Skovsmose, Educação Matemática Crítica: a questão da democracia (pp. 127 - 153). Campinas: Papirus.

Chaiklin, S. (2012). A conceptual perspective for investigating motive in cultural-historical theory. In M. Hedegaard, A. Edwards \& M. Fleer. Motives in children's development: cultural-historical approaches (pp. 209 - 224). New York: Cambridge University Press.

Duarte, N. (2004). Formação do indivíduo: consciência e alienação. O ser humano na Psicologia de A. N. Leontiev. Caderno Cedes, 24(62), 44-63.

Freitas, M. T. (2002). A abordagem sócio-histórica como orientadora da pesquisa qualitativa. Cadernos de pesquisa, (116), 21-39.

Kozulin, A. (2002). O conceito de atividade na Psicologia Soviética: Vygotsly, seus discípulos e seus críticos. In H. Daniels, Uma introdução a Vygotsky (pp. 111-137). São Paulo: Edições Loyola.

Lampreia, C. (1999). Linguagem e atividade no desenvolvimento cognitivo: algumas reflexões sobre as contribuições de Vygotsly e Leontiev. Psicologia: reflexão e crítica, $12(1), 225-240$.

Leontiev, A. (1978a). O desenvolvimento do psiquismo. Lisboa: Horizonte universitário.

Leont'ev, A. N. (1978b). Activity, consciousness and personality. New Jersey: Prentice-Hall.

Mendonça, S. G. (2011). A crise de sentidos e significados na escola: a contribuição do olhar sociológico. Caderno Cedes, 31(85), 341-357.

Moraes, R. (2003). Uma tempestade de luz: a compreensão possibilitada pela análise textual discursiva. Ciência \& Educação, 9(2), 191-211.

Ponte, J. P. (2009). Investigações matemáticas na sala de aula. Belo Horizonte: Autêntica.

Rey, F. G. (2007). As categorias de sentido, sentido pessoal e sentido subjetivo: sua evolução e diferenciação na teoria histórico-cultural. Psicologia na Educação,(24), 155-179.

Skosmose, O. (2000). Cenários para investigação. Bolema, 13(14), 66-91.

Vigotski, L. S. (2000). A construção do pensamento e da linguagem. São Paulo: Martins Fontes. 